\title{
Research on the Self-management Mechanism of Foreign students: A Case study of Shanghai Polytechnic University Sun YAN*
}

Shanghai Polytechnic University, 2360 Jinhai Road, Pudong Shanghai China sy701017@163.com

*Corresponding author

Keywords: Foreign students, Sense of belonging, Ideology, Self-management, Mechanism construction

\begin{abstract}
With the development of China's Belt and Road international strategy, more and more foreign students choose to study in China, which has further promoted the development of studying in China, and put forward higher requirements for the management of foreign students in Chinese universities. At present, there are some universal problems in the management of foreign students in domestic universities which the management mechanism is not mature enough. Taking Shanghai Polytechnic University as an example, this paper analyzes the present situation of the management of foreign students, and finds that the existing management mode determines students' poor sense of professional belonging, the college does not carry out the ideological education of foreign students, and the university is lack of self-management service system for foreign students. In view of the above problems, the author puts forward the construction path of the self-management mechanism for foreign students, that is, to formulate and perfect the relevant system of self-management of foreign students, to strengthen emotional input and correct guidance, and to realize self-management with students as the main body.
\end{abstract}

\section{Introduction}

The level of self-management is an important factor which affects the social adaptation effect, activity performance and mental health of individuals ${ }^{[1]}$. Student Self-management is high level pursuit under the constant development of higher education. Spencer argues education duty is to prepare for the people's full life in his book the Theory of Education. He thinks the purpose of management is not to cultivate a person who needs others to manage himself, but to cultivate a person who can be self-governing ${ }^{[2]}$. Foreign students who come to China to receive higher education have their own principles and angles to judge things. In general, foreign students also have a clear sense of democracy and ideas. Based on the principle of self-management, self-education and self-service for foreign students, domestic university should strive to stimulate their enthusiasm in the process of management, and give full play to the active role of the backbone 
of foreign students. Guiding and supporting the Self-management mechanism construction in the Education of Foreign students is an urgent problem to be solved in the process of internationalization of domestic universities.

\section{Literature Review}

\section{The concept of self management}

Self-management is a process in which individuals actively use cognitive and behavioral strategies to manage their own thoughts, emotions, behaviors and environments ${ }^{[3]}$. There are two kinds of self-meaning in self-management. One is the ego that acts as an agent and to some extent, involves subconscious activities. The other is self-self, which is reflexive, as an object or object ${ }^{[1]}$. The research on self-management in the field of education is mainly to improve the learning effect by improving learners self-management ability ${ }^{[4]}$.

\section{Self-management model and related research}

\section{Self-management model of goal adjustment}

Self-management researchers in the paradigm of goal regulation or goal management believe that establishing appropriate goals (long-term or short-term goals) for themselves is an important first step in effective self-management. Research shows that long-term goals are closely related to students' performance in school. Students with long-term goals will link their efforts to long-term goals, and get higher grades in academic performance than other students. Long-term goals help students move beyond the immediate situation and its unpleasant demands and distractions ${ }^{[5]}$. However, without the support of short-term goals, long-term goals are also difficult to achieve. Those who pursue a range of short-term goals gain a sense of self-efficacy as they approach and reach them ${ }^{[6]}$. So the best thing to do for effective self-management is to have both long-term and short-term goals ${ }^{[1]}$.

\section{The model and content of self-management for foreign students}

With regard to the self - management model of foreign students, domestic research mainly focuses on class management, student groups, school attendance and so on. First of all, the class is the basic unit of the school, and the university class is the basic organization for the students to acquire a sense of belonging in the school. The class collective is also an important base for the foreign students of domestic universities to complete their self-management. However, with the implementation of the complete credit system, the concept of class becomes more and more weakly in universities. The international student group is the important link of self-management for foreign students in domestic university. At this stage, many foreign students in our country or universities have a single foreign student group organized spontaneously by foreign students, and some foreign students groups in schools have also played a role, but they are still unofficial, lack of management, etc. The school management department can manage and supervise these groups, and also realize 
the self-management, self-education and self-service of foreign students. Finally, part-time work study is one of the most important ways for foreign students in domestic universities to achieve self-management ${ }^{[4]}$.

Some studies have also noted that with the increasing size of Chinese students , the contradiction between limited accommodation resources and rapidly increasing students is becoming more and more prominent. Therefore, in the related aspects of student services, such as student accommodation management, it is suggested to introduce a socialized intelligent student logistics management system, fully mobilize the social resources inside and outside the school to serve foreign students, and alleviate the contradiction of demand. Improve service quality. Germany, as the world's third largest destination for international students, deserves to learn from this experience. Germany has a special, independent from the university of autonomous services to provide international students with a full range of living services, such as food, clothing, housing and transportation $^{[7]}$, to solve the worries of foreign students.

To sum up, the self-management in foreign students education is not to let students manage themselves without any restrictions and guidance. No matter class organization or student association, must have the corresponding rules and regulations to restrict, the school should assist the student to contact each kind of inside and outside the school resources, give the instruction in the specialized knowledge, the activity plan and other aspect. At the same time, we should pay attention to respect different students' cultural differences, individual differences, and improve the enthusiasm of foreign students to participate ${ }^{[8]}$. However, previous studies did not address the individualized path of self-management that was explored because of differences in foreign students' culture and scale. Therefore, it is necessary to study the characteristics of foreign students in one university according to the current situation.

\section{Management of Foreign students in Shanghai Polytechnic University}

Shanghai Polytechnic University has developed foreign student education since 2011, and has been basically stable for the composition of academic bachelor, exchange, language and short-term program students. According to the 2017 statistics, the number of foreign students in university is 269, the number of countries is 27. Among them, academic bachelor students are mainly from Mongolia, Kazakhstan and Laos, Zimbabwe and Cameroon. Exchange students are mainly from Germany, Belgium, Finland and Sweden. Short-term program students are mainly from Korea, Russia, and Australia. The self-managed foreign students involved in this study are mainly academic bachelor students and exchange students. Based on the in-depth interviews and questionnaires between the relevant functional departments of the school, the management, professional teachers, counsellors and foreign students, it is found that the management of foreign students' education and teaching in our school has not realized intensive management, professional education has not established a systematic education system that conforms to the characteristics of 
foreign students, At the same time, there is a lack of self-management service system for foreign students.

\section{Existing management model determines the poor belonging sense of foreign students}

The management of foreign students' education and teaching in the university adopts the mode that the Office of Foreign students Affairs is responsible for enrollment, entry \& exit, and related affairs coordination, the College is responsible for the management of education and teaching. Under the complete credit system, foreign students in specialized colleges do not have separate classes as Chinese students do. They attend different professional and elective classes according to their credit requirements. For the exchange students, the foreign student affairs office is in charge of daily management, and the specialized college is responsible for teaching. Since exchange students need to be taught in English, the exchange students are taught separately by the College of Professional Studies in the absence of Chinese students who can follow the course. According to the depth interview of the students, foreign students generally feel the difference of professional sense of belonging, it is difficult to enter a better learning and life state, and it is easy to develop special psychological states such as academic burnout and emotional anxiety

\section{The college does not carry out the ideological education of foreign students}

At present, Shanghai Polytechnic University attaches great importance to the professional education of foreign students, but the college does not consider the ideological education of foreign students. In fact, cultural differences have great influence on the daily learning and life of foreign students. However, in the process of professional teaching management, the colleges didn't combine foreign students' professional learning with cultural awareness. An education system "professional learning + cultural and ideological cognition" has not been established for foreign students. Some teachers do not want to communicate with foreign students in addition to teaching.

\section{Lack of self-management service system for foreign students}

In view of the daily management of foreign students, many colleges and universities on the one hand set up foreign student counselors, to give foreign students spiritual encouragement, active contact and help them overcome the problems of culture, customs and habits when they first came to China. On the other hand, play the role of foreign students' self - management, select positive elements from foreign students, assist foreign students in management of foreign students , play their subjective initiative and listen to their opinions and suggestions on management . However, the foreign students in SSPU have few self-management organizations and lack of interaction with other Chinese student organizations. There are no special counselors for foreign students in the colleges.

According to Maslow's theory of hierarchy of needs, there are five levels of human needs: physical needs, security needs, social needs, respect needs and self-actualization needs ${ }^{[9]}$. After their own physiological and security needs have been met, students seek higher levels of 
satisfaction, such as understanding Chinese culture, making Chinese friends, enhancing their professional ability, and thus realizing the value of life, meeting the needs of self-actualization. The common goal is to learn Chinese to learn about China, or to improve professional skills, or both, bringing together people of different languages, nationalities, and beliefs from all over the world, Living and studying under the same standards in the same environment. Studies have shown that people's irrational internal motivation will be more and more restricted after early childhood, and many of the things they do are not dynamic in nature, but affected by social pressure. People will take on jobs and new responsibilities that they don't want to do ${ }^{[10]}$. Therefore, it is necessary and able for foreign students to monitor, encourage and help each other in their study and life through a model of self-management, so as to make common progress.

\section{The Path of Self-management Mechanism Construction for Foreign Students}

\section{Formulating and perfecting the system of self management of foreign students}

System is the cornerstone and guarantee of management. In order to realize effective management, rules and regulations must be first established. The Office of Foreign Student Affairs of the university takes the lead in formulating the self-management system for foreign students. While giving foreign students the right of self-management, it also holds the direction for the self-management of foreign students, restricts the self-management behavior of foreign students, and follows the regulations of the national laws and regulations, the university discipline and rules. For example, to further improve the work flow of enrollment of foreign students and Shanghai municipal government's Scholarship for foreign students, revise and issue the Handbook for students of foreign students (Chinese / English version), propagandize and implement the regulations on the Management of Student status and the regulations on the examination of courses for foreign students. After the implementation of the system, the management also supervises the implementation of the system, listens carefully to the feedback from foreign students in the process of implementing the system, and further improves the system according to the feedback.

\section{Human oriented and strengthening emotional input and correct guidance}

The management department should carry out the human - oriented management model for foreign students. The education of foreign students should not only teach them scientific knowledge, but also develop their correct world and life outlook, realize the linkage mechanism of the Office of Foreign Student Affairs, administration office, the college, the counselor and the academic tutor. 
Management should be good at discovering the leader appearing in the students, who often have strong prestige and appeal in their classmates, and often have higher comprehensive abilities and EQ . Ideological and management work can start from this part of the students with establishing emotions with them, imperceptibly giving them the correct guidance in learning and life. These excellent students will be a good helper for managers, good friends of the students, and closer relationship between teachers and students.

\section{Taking students as the main body to realize Self-management}

The management department should attach importance to the personality development of foreign students and make great efforts in students' self-management and independent activities. Foreign students are not the passive domination of the school, but the active participation of the individual. The students' association and alumni association should be set up, the responsible person of grade, the head of dormitory and the graduate student should be set up to carry out work, study, life and other all-round self-management. In fact, it regards foreign students as the main body of campus culture, giving full play to their enthusiasm and creativity, so as to effectively realize self-management. Take enriching the activities of the international students association as the grasp, with language activities as the characteristics of the special activities; take cultural activities as a brand, strengthen the connotation of construction, enhance the influence of the activities of the sorority cultural exchanges, sports, art exhibition, social practice and other activities. At the same time, select experienced personnel as the association of the instructor, strengthen the student backbone training, establish complete the system of activities planning, training, advocacy, implementation and evaluation to enrich the campus culture system of international students.

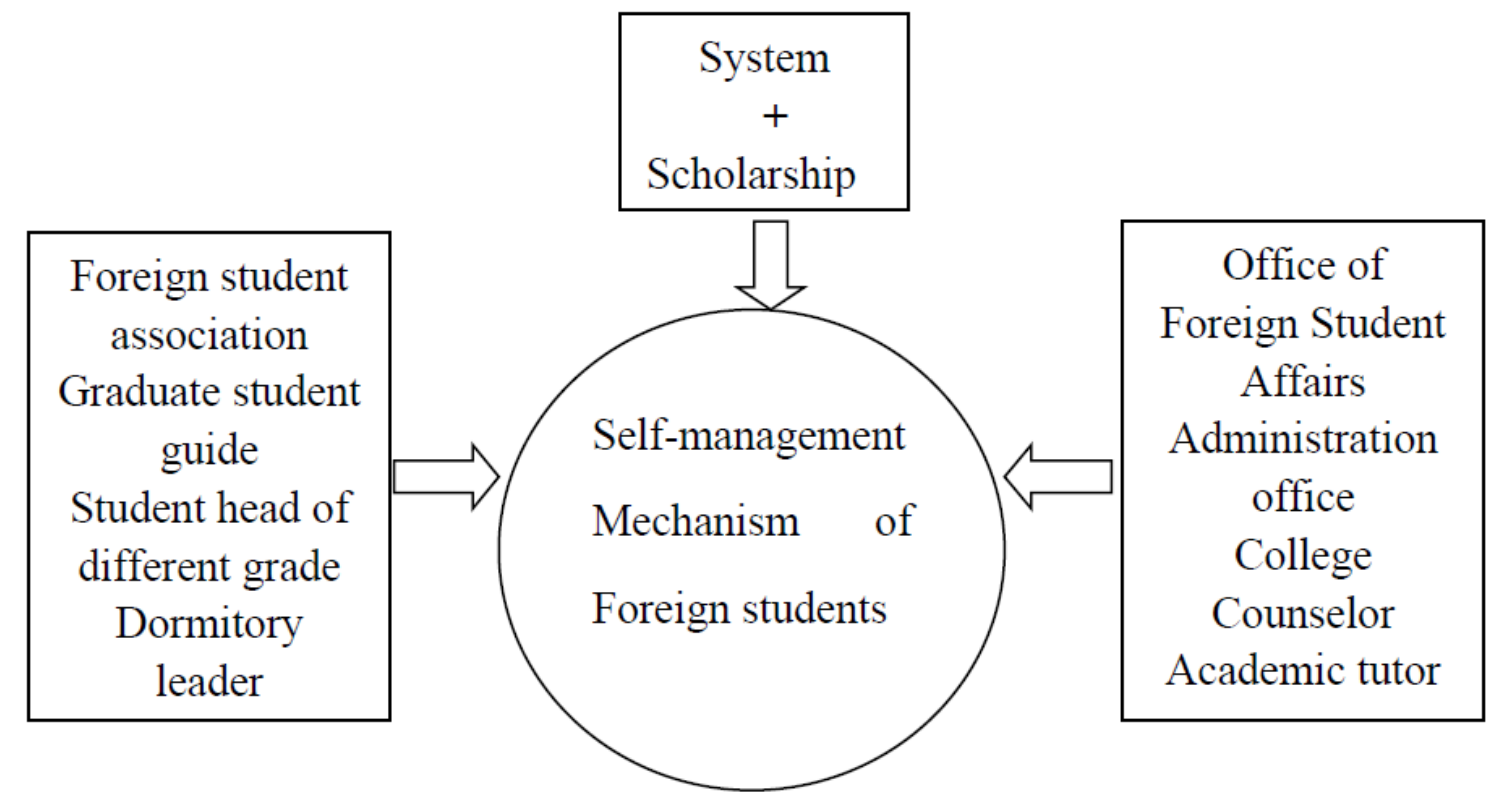

Figure 1 Path of Self-management Mechanism Construction for Foreign Students 


\section{Conclusion}

The education of foreign students is an important part of the construction of national soft power. Strengthening the management of foreign students education is an important way to improve the level of running a university. At present, the education of foreign students coming to China is in the process of rapid development facing new situations, needs innovation of educational management to change the traditional thinking and promote the development of foreign students' education management. The exploration and construction of the self-management mechanism of foreign students in our university will certainly make the management of foreign students achieve the good effect.

\section{Acknowledgement}

This research was financially supported by the Shanghai Polytechnic University Science Foundation (Approval No.: XXKPY1607).

\section{References}

[1] Yiming Wang, Yu Jin, A review of self-management research, J. Psychological Science, 25 (2002) 453-456.

[2] Chaoyang Li, Education: Preparing for a perfect life----an introduction to Spencer's theory of education, J. Educational Science Research, 11 (2012) 76-78.

[3] Schunk, D. H., Zimmerman, B. J., Social origins of self-regulatory competence, J. Educational Psychologist. 32 (1997) 195-208.

[4] Shenchen Wu, Discussion on self-management mechanism of foreign students in universities, J. Managers Journal. 9 (2016) 437-438.

[5] Volder, M. L. D., Lens, W., Academic achievement and future time perspective as a cognitive-motivational concept, J. Journal of Personality and Social Psychology. 42 (1982) 566-571.

[6] Bandura, A., Schunk, D. H., Cultivating competence, self-efficacy, and intrinsic interest through proximal self-motivation, J. Journal of Personality and Social Psychology. 41 (1981) 586-598.

[7] Jin Sun, Haiqin Ning, Explaining the charm of Germany as destination for studying abroad----With an analysis of its internationalization policies to attract overseas students, J. Comparative Education Review, 311 (2015)1-8.

[8] Fei You, International students' administration from the perspective of "The Belt and Road Initiative" , J. Journal of Nanjing University of Science and Technology (Social Science), 30 (2017) $36-40$ 
[9] Frame, D., Maslow's hierarchy of needs revisited, J. Interchange. 27 (1996) 13-22.

[10] Ryan, R. M., Deci, E. L., Self-determination theory and the facilitation of intrinsic motivation, social development, and well-being, J. American Psychologist. 55 (2000) 68-78. 